\author{
SERIES 'OCCUPATIONAL ASTHMA' \\ Edited by C. Mapp
}

\title{
Definition and diagnosis of occupational asthma
}

\author{
A. Cartier
}

\begin{abstract}
Definition and diagnosis of occupational asthma. A. Cartier. CERS Journals Ltd 1994. ABSTRACT: Asthma is the most frequent occupational lung disease. The diagnosis of occupational asthma, defined as variable airways narrowing, causally related to exposure in the working environment to specific airborne dusts, gases, vapours or fumes, needs to be confirmed by objective means. This article reviews the different steps of investigation which are: history, pulmonary function tests, immunological tests, monitoring of peak expiratory flows and nonallergic bronchial responsiveness and, finally, the gold standard, specific bronchial provocation.

Eur Respir J., 1994, 7, 153-160.
\end{abstract}

Correspondence: A. Cartier, Hôpital du Sacré-Coeur, 5400 Boul. Gouin Ouest, Montréal, PQ, Canada, H4J 1C5.

Keywords: Occupational asthma, occupational lung disease, peak expiratory flow, specific bronchial challenge

Received: July 161993

Accepted for publication September 121993

\section{Definition}

Asthma is one of the most frequent chronic respiratory conditions, and it is thus not surprising that physicians encounter patients who develop or show increased severity of asthma during their adult working life. It is important to determine in these situations whether work is causally related to the development of asthma. Indeed, asthma is now the most common cause of work-related respiratory disease in industrialized countries $[1,2]$.

As proposed by NEWMAN-TAYLOR [3], occupational asthma can be defined as "variable airways narrowing, causally related to exposure in the working environment to airborne dusts, gases, vapours or fumes". Two elements in this definition are important. The agent (identified or not) should be specific to the workplace and be causally related to the disease [3-7]. This definition thus excludes asthma triggered by irritant mechanisms, such as cold air or exercise. A previous history of asthma does not exclude the diagnosis of occupational asthma. Other forms of variable airflow obstruction have also been described, i.e. reactive dysfunction syndrome (RADS) $[8,9]$ (developed after acute exposure to high concentrations of gases or fumes), and by byssinosis [10] (related to exposure to cotton dust).

\section{Investigation}

As opposed to the traditional pneumoconiosis, where the diagnosis is based only upon exposure history and chest radiograph abnormalities, occupational asthma can be confirmed by objective means. When a diagnosis of occupational asthma is made, the worker should be withdrawn from work to avoid further deterioration of asthma and to minimize long-term sequelae [11, 12]; this stresses the importance of a proper diagnosis.

The different steps involved in the investigation of occupational asthma are: history, pulmonary function tests, immunological tests, combined monitoring of peak expiratory flows (PEF) and bronchial responsiveness, specific bronchial challenges. Excellent reviews including recent European guidelines $[4,5,13,14]$ have also been published.

\section{History}

The questionnaire is the basic, essential tool used in most epidemiological surveys and all individual assessments.

The classical history of occupational asthma is one of a worker whose asthma is worse at work, improving over weekends or holidays. However, this pattern is often absent, as symptoms are also usually present outside the workplace, being triggered by exposure to irritants such as cold air, fumes or exercise. In many cases, symptoms are even more severe at home, waking the subject at night, and weekends may not be long enough to allow for recuperation. A previous history of asthma may also postpone the diagnosis.

The concomitant occurrence of rhinoconjunctivitis at work and, occasionally, of skin rash (urticaria), especially in a worker exposed to high molecular weight chemicals who develops asthma, is surely suggestive of occupational asthma. CHAN-Yeung and co-workers $[15,16]$ recently showed that rhinitis occurring in workers exposed to red cedar may be a predisposing factor for developing occupational asthma [15]. Symptoms may develop after only a few weeks or after several years, following a duration of exposure which tends to be shorter in the case of low molecular weight chemicals [16].

However, a history suggestive of occupational asthma, even in a worker exposed to a known sensitizer, is not sufficient to make the diagnosis: questionnaires are sensitive but not specific tools. Indeed, we recently showed in a prospective study of 162 workers referred for occupational asthma, that even in the hands of expert physicians, the predictive value of a positive questionnaire was only $63 \%$, whilst the predictive value of a negative questionnaire 
was better, i.e. $83 \%$ [17]. Therefore, in more than one third of cases, objective testing showed that the subjects did not have occupational asthma, although the initial questionnaire had been suggestive. It is also our experience that closed questionnaires, administered by technicians or nurses for epidemiological surveys, are unsatisfactory [18-21].

\section{Pulmonary function tests and diagnosis of asthma}

Although the diagnosis of asthma can be confirmed by the presence of reversible airways obstruction, e.g. increase of forced expiratory volume in one second $\left(\mathrm{FEV}_{1}\right)$ greater than $15 \%$ after a beta ${ }_{2}$-agonist, most workers investigated for occupational asthma have normal spirometry when seen in the clinic. Furthermore, pre- and post-shift monitoring of $\mathrm{FEV}_{1}$ has not proved sensitive or specific enough to be a useful tool in the investigation of occupational asthma [20-22].

Bronchial responsiveness is the hallmark of asthma, but it is also present in other conditions, such as rhinitis and chronic obstructive lung diseases. Therefore, the presence of increased bronchial responsiveness does not confirm the diagnosis of occupational asthma. It may suggest that the subject has occupational asthma, common asthma, or one or other of the conditions listed above. There is a need for further confirmation of work-related asthma. On the other hand, the absence of bronchial hyperresponsiveness as assessed shortly (minutes, hours) after a workshift in a worker who complains of symptoms, virtually excludes occupational asthma. However, even in the presence of occupational asthma, bronchial responsiveness may be normal in a worker who has left work for several days (a weekend may be enough [23] or weeks/months). Return to work or even a specific inhalation test will then increase the bronchial responsiveness in the asthmatic range [24, 25].

\section{Immunological testing}

The presence of immediate skin reactivity or increased specific immunoglobulin $\mathrm{E}$ or $\mathrm{G}$ (IgE or $\mathrm{IgG}$ ) antibodies may reflect exposure and/or sensitization, but it does not imply that the target organ (the bronchi in this instance) is involved. This has been shown for common allergens and occupational sensitizers, such as snow-crab [26], psyllium [21] and isocyanates [27]. With high molecular weight chemicals, such as cereals or psyllium, negative skin tests to these allergens cannot entirely exclude the diagnosis of occupational asthma, but does make it unlikely. The worker may still be sensitized to another agent found in the workplace or to another component of the offending agent. Indeed, in snow-crab workers' asthma, the odds for the presence of occupational asthma in a subject with positive skin tests to snow-crab extract or radioallergosorbent test (RAST) ratio $>4.5$ were, respectively, 69 and $79 \%$, whereas the odds for the absence of occupational asthma in a subject with negative skin test or RAST ratio $<4.5$ were 76 and $73 \%$, respectively, [26]. With low molecular weight chemicals, such as isocyanates and red cedar, negative skin tests or specific $\operatorname{IgE}$ or $\operatorname{IgG}$ do not refute or confirm the diagnosis of occupational asthma $[27,28]$; skin tests are also usually unavailable.

\section{Monitoring of peak expiratory flows and nonallergic bronchial responsiveness}

The availability of portable, inexpensive devices has allowed physicians to monitor PEF at work and away from work. This approach was first used in the investigation of work-related asthma by BURGE et al. [29, 30]. Coupling $\mathrm{PEF}$ monitoring and changes in nonallergic bronchial responsiveness (NABR) for periods at work and away from work has also been proposed [31-33] (fig. 1).

The sensitivity and specificity of PEF monitoring in confirming occupational asthma were assessed prospectively in two studies using specific inhalation challenges, which are considered the gold standard, as a point of comparison [32, 33]. Sensitivity and specificity were 81-89 and 74-89\%, respectively. In a recent study [34], we showed that sensitivity and specificity of PEF monitoring was optimal when PEF was measured every $2 \mathrm{~h}$ at work and away from work. Studying the deterioration of asthma while at work is still the best way to evaluate changes in PEF $[33,35]$. The poor sensitivity or specificity of PEF monitoring in certain subjects, as compared to specific bronchial challenges, can be explained. Even if performed under the close supervision of a technician, PEF may greatly underestimate or overestimate changes in airway calibre as assessed by $\mathrm{FEV}_{1}[36,37]$; furthermore, PEF are effort dependent, and thus require the collaboration of the worker, which is not always obtained, due to fear of losing his job or malingering in order to receive compensation benefit.

To be able to draw some conclusions, the minimum period of monitoring should be at least two weeks at work and away from work. In certain situations, particularly when asthma is severe or when the nature of the offending agent is unknown or intermittent, the interpretation of the monitoring may be difficult [33]. Subjects should be asked to take their beta ${ }_{2}$-agonists on demand only, but should continue their inhaled steroids and, if taken, their theophylline at the same dosage throughout the entire monitoring. Reduction of inhaled steroids upon return to work may be associated with deterioration of asthma and reduction in PEF, which may be mistaken as diagnostic of occupational asthma. In severe asthmatics, it may be necessary to withdraw the subject from work until his asthma is under control and on minimum treatment before returning him to work; deterioration of asthma may then suggest that asthma is caused by the work environment.

The association of NABR monitoring to PEF monitoring at work and away from work is now frequently used in the investigation of occupational asthma [31-33]. Indeed, whereas exposure to irritants does not induce marked and prolonged changes in NABR, occupational asthma may be associated with significant and often long-lasting changes in NABR [38] (fig. 1). However, COTÉ et al. [32] and PERRIN et al. [33] showed that this measure did not improve 
a)

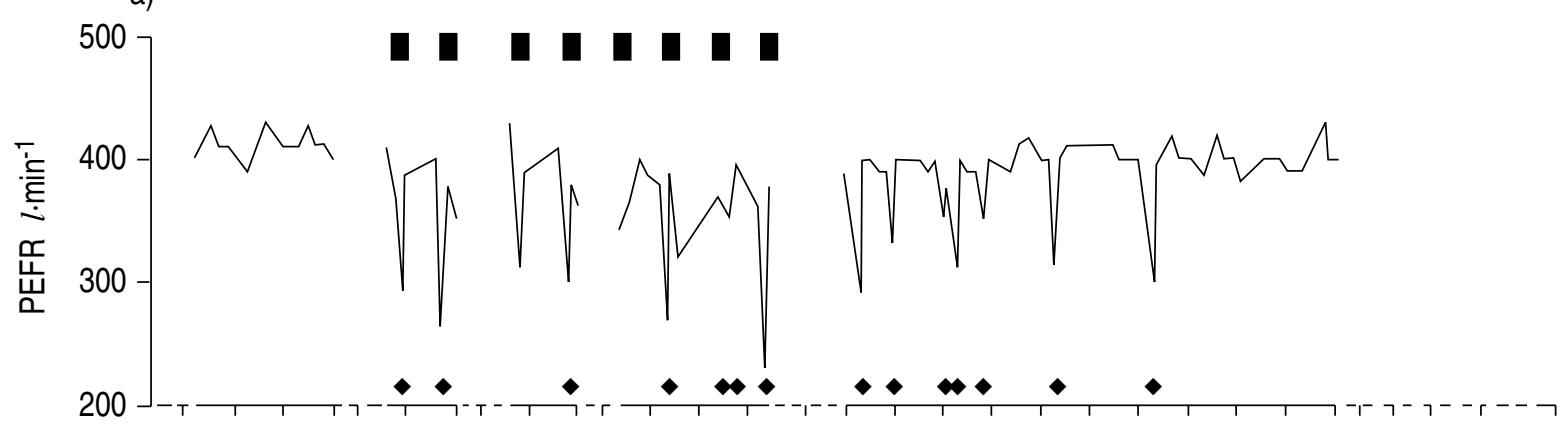

b)

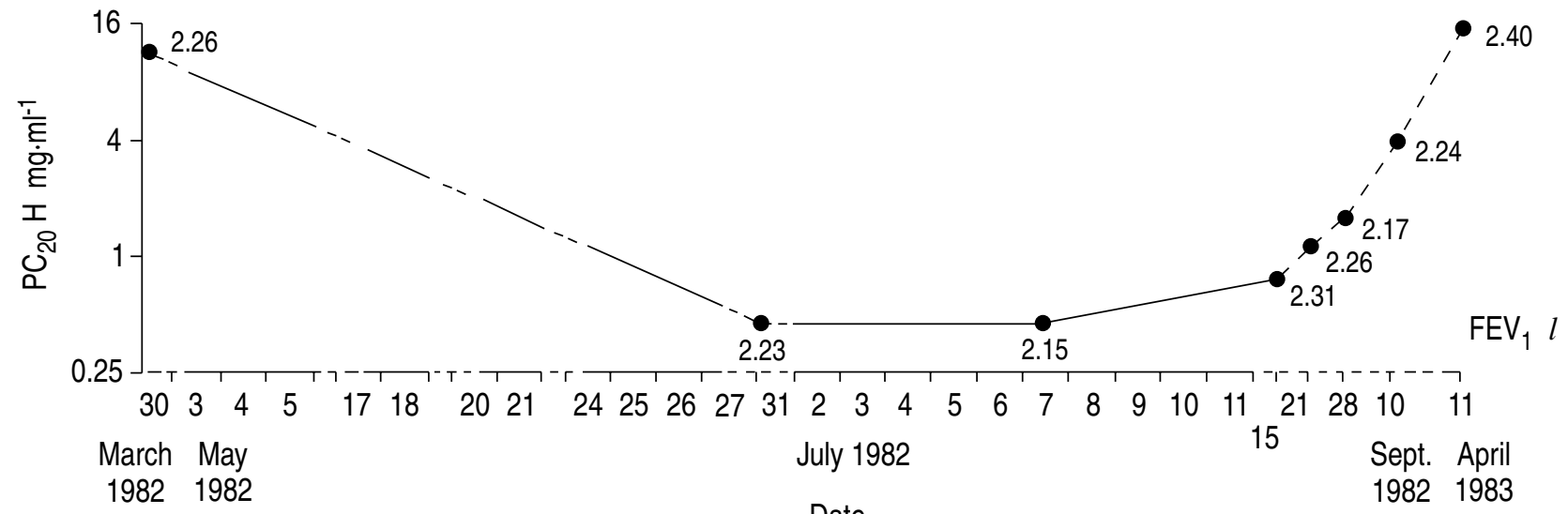

Fig. 1. - Combined monitoring of: a) peak expiratory flow rate (PEFR); and $\mathrm{b}$ ) $\mathrm{PC}_{20} \mathrm{H}$, in the same snow-crab processing worker before and after return to work. Squares ( $\mathbf{\square})$ represent the time spent at work, and lozenges $(\bullet)$ illustrate the use of inhaled salbutamol. Baseline FEV $\mathrm{V}_{1}$ values before each histamine inhalation test are illustrated. They vary by no more than $6 \%$ from one test to another. Return to work was associated with deterioration of PEFR and increase in NABR as shown by decrease in $\mathrm{PC}_{20}$, which gradually recovered over days for PEFR and months for NABR. $\mathrm{PC}_{20} \mathrm{H}$ : provocative concentration of histamine producing a $20 \%$ fall in $\mathrm{FEV}_{1}$; $\mathrm{FEV}_{1}$ : forced expiratory volume in one second; $\mathrm{NABR}$ : nonspecific airways responsiveness. (Reprinted from [18]).

the sensitivity or specificity of PEF monitoring in diagnosing occupational asthma. When changes in PEF are associated with parallel changes in NABR, the diagnosis of occupational asthma is highly probable. If the monitoring of PEF and NABR are discordant, it may be prudent to perform specific bronchial challenges in the workplace or in the laboratory.

Although monitoring of PEF and NABR are useful tools, they are time-consuming, require the subject's collaboration and may be hazardous in workers giving a history of severe asthma at work, as exposure may not be measured as easily as when the challenge is performed in the laboratory. They are particularly useful as a screening procedure, when the worker is exposed to several sensitizers or when the offending agent is unknown.

\section{Specific bronchial challenges}

These tests are still considered the gold standard in the confirmation of the diagnosis of occupational asthma [4, 14, 39-43]. Originally performed in the laboratory and aimed at mimicking work exposure [44], these tests can also be carried out in the workplace [18, 45].

These tests are limited to specialized centres with trained personnel and where resuscitative measures are available. They should always be carried out under the close supervision of an expert physician. The exposure chambers should be well-ventilated and isolated to minimize exposure to the personnel. In most subjects, the tests can be carried out on an out-patient basis, restricting hospitalization in subjects who have severe late reactions. In all cases, spirometry $\left(\mathrm{FEV}_{1}\right.$ and forced vital capacity $\left.(\mathrm{FVC})\right)$ should be monitored on a control day to ensure stability of airway calibre. In more severe asthmatics, the subject should first be observed for at least $8 \mathrm{~h}$ on a nonexposed day, whereas most subjects can be exposed on the first day to a control irritant, e.g. lactose powder, paint diluent, resin $[39,41] . \mathrm{FEV}_{1}$ is monitored at baseline, and then every $10 \mathrm{~min}$ for one hour, every $30 \mathrm{~min}$ for one hour, and then hourly for at least $8 \mathrm{~h}$ after the end of exposure. If the subject shows too much variability of $\mathrm{FEV}_{1}$ during the control day, the tests should be postponed and asthma should be controlled by increasing treatment; increasing the dose of inhaled steroid is usually enough, sometimes theophylline is needed to ensure stability of $\mathrm{FEV}_{1}$. At the end of the control day, we usually perform a methacholine challenge test to determine the level of NABR as assessed by the provocative dose inducing a $20 \%$ fall in $\mathrm{FEV}_{1}\left(\mathrm{PC}_{20}\right)$. This value may help to determine the starting concentration to the offending agent on the next day, the lower the $\mathrm{PC}_{20}$, the lower the exposure [46]. Whilst FEV is the standard parameter used to assess airway calibre, $\mathrm{PEF}$ are not reliable enough as they may underestimate or overestimate changes [36]. 
a)
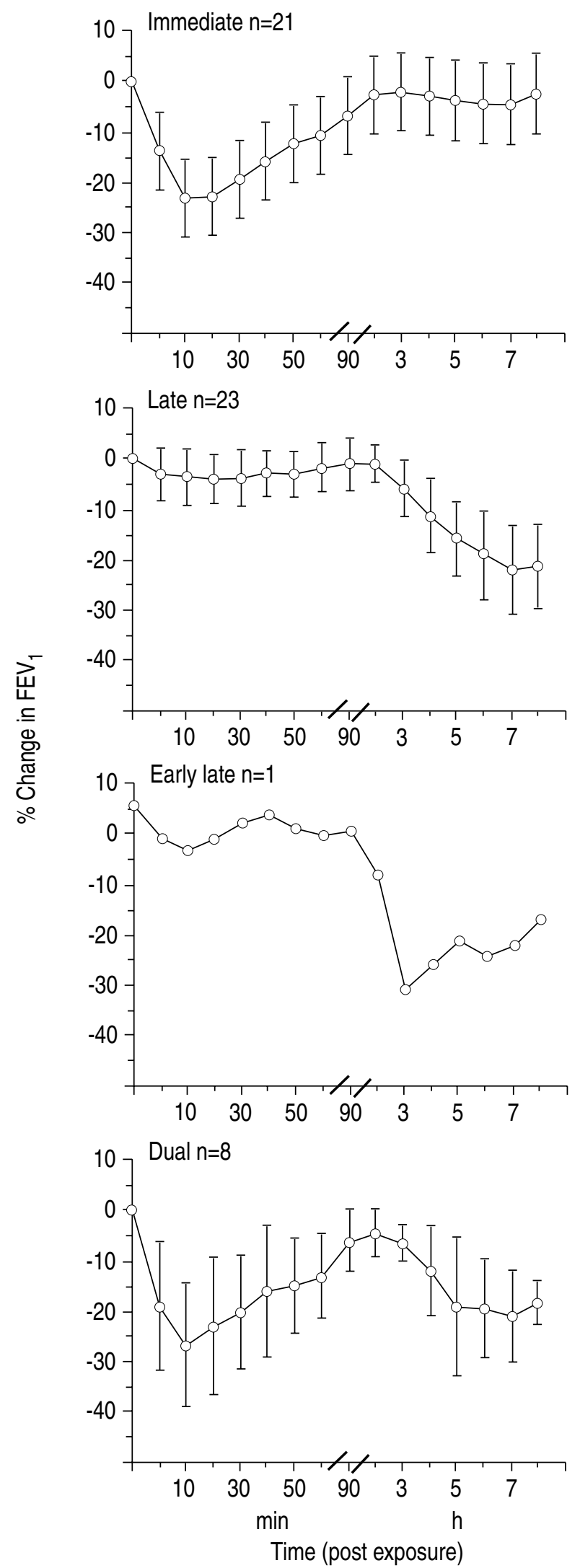

b)
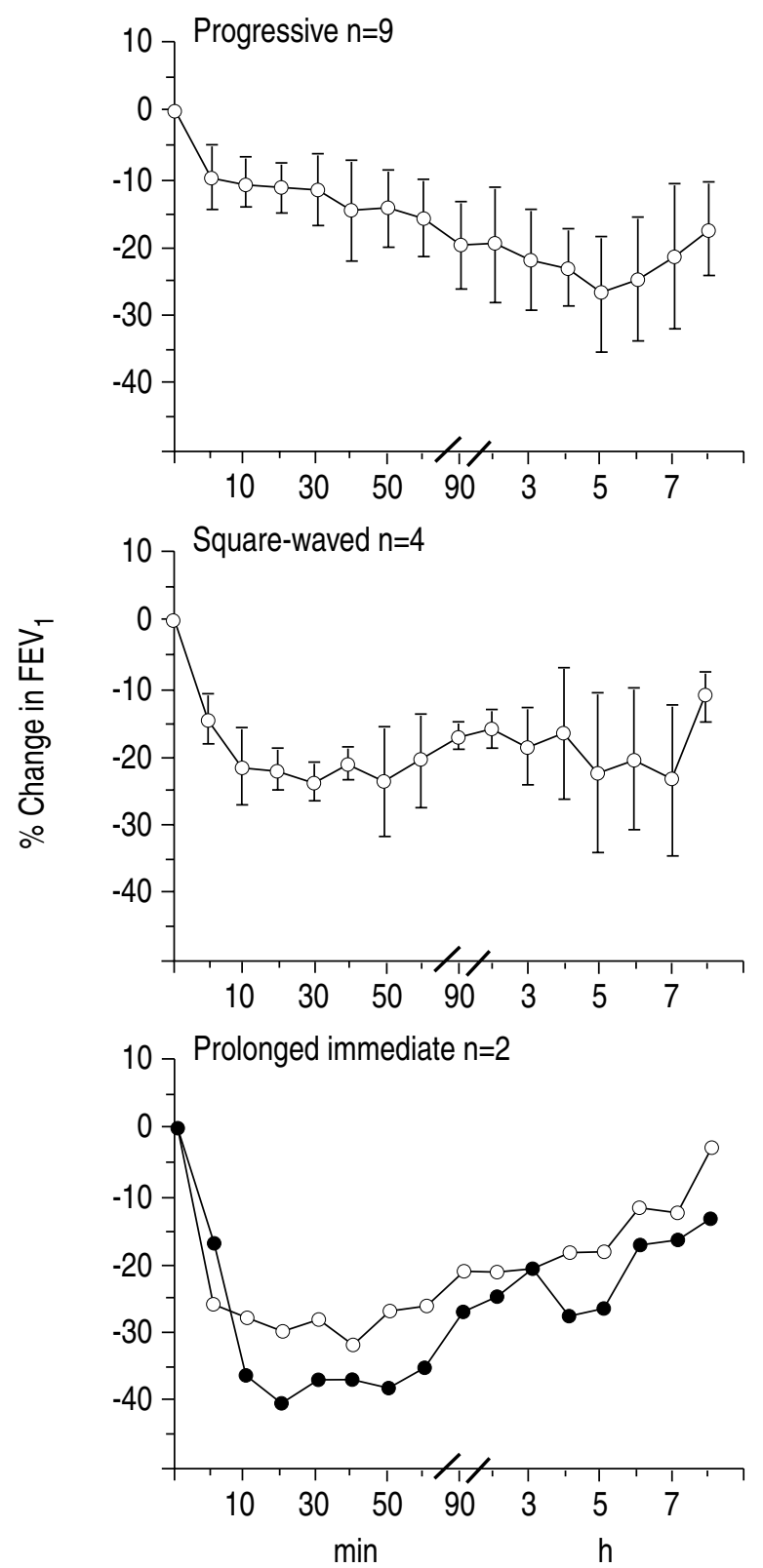

Time (post exposure)

Fig. 2. - Mean \pm SD or individual values of the percentage change in $\mathrm{FEV}_{1}$ as a function of time since exposure: a) for the four typical patterns of reactions (see test for definition); b) for the three atypical patterns of reactions (see text for definition). The number of subjects for each pattern is shown. Note variation in time axis. $\mathrm{FEV}_{1}$ : forced expiratory volume in one second. (Reprinted from [52]). 
Drugs should be withheld before specific bronchial challenges according to standard recommendations [41]. Beta $_{2}$-agonist (oral and inhaled) and ipratropium bromide must be withheld for $8 \mathrm{~h}$. In most subjects, long-acting theophylline should be withheld for $48 \mathrm{~h}$ (or $72 \mathrm{~h}$ for once-a-day tablets), but may have to be continued in subjects who show excessive variability in their spirometry throughout the day they are withheld. Inhaled corticosteroids, sodium cromoglycate and nedocromil sodium should be continued, but taken only in the evening of each challenge day at the same total dose, to avoid exacerbation of asthma through withdrawal of medication.

In the laboratory, specific bronchial challenges can be performed in several ways, depending on the nature of the agent, i.e. powder, aerosol, liquid or gas [39]. With powders, such as flour, psyllium or red cedar, the subject may be exposed to a fine dust, mimicking work exposure, either by pouring the dust from one tray to another [44], or by using a dust generator, which allows proper monitoring, regulation of exposure, and establishment of doseresponse curves, and reduces the risk of severe and/or irritant reactions $[47,48]$. Alternatively, the worker may be exposed to an aerosol of a crude extract [49, 50]. Exposure to non-powder agents is usually carried out by reproducing the work environment, $e . g$. by nebulizing an aerosol of hexamethylene diisocyanate or by having the worker breathe over a bottle of methacrylate glue. Isocyanates can be generated in their gaseous form in a small chamber, to improve safety of exposure [51]. Whenever possible, the level of exposure should be monitored to avoid high exposure and, therefore, irritant reactions.
Baseline spirometry on each exposure day should be reproducible, i.e. $\pm 10 \%$ of the control day. Exposure should always be progressive (one breath, 10-15 s., 1 $\min , 2 \mathrm{~min}, 5 \mathrm{~min}$, etc.). The total duration of exposure is a function of the type of agent. For high molecular weight chemicals with which positive skin tests can be elicited, exposure is increased progressively for up to $2 \mathrm{~h}$ with intermediate functional assessments. As on the control day, spirometry is assessed immediately and 10 min after each period of exposure. A significant reaction is defined as a $20 \%$ fall in $\mathrm{FEV}_{1}$. With low molecular weight chemicals, such as isocyanates, which are more often associated with isolated late responses [52], exposure should be more gradual and spread over a few days: one breath, $15 \mathrm{~s}, 45 \mathrm{~s}$ and $2 \mathrm{~min}$ on the first day; $30 \mathrm{~min}$ on the second day; and $2 \mathrm{~h}$ on the third day. However, this pattern of exposure may be modified by reducing the duration of subsequent exposures if there is a suggestion that the subject is starting to react. If there is no significant variation in $\mathrm{FEV}_{1}$ on the last exposure day, the NABR should be reassessed at the end of that day; if there is no significant change from baseline, exposure can be stopped, whereas if $\mathrm{PC}_{20}$ is significantly lower, exposure is repeated the next day for up to $4 \mathrm{~h}$.

Typical patterns of bronchial reactions have been described [44, 52] (fig. 2a). "Immediate reactions" are maximal 10-30 min after exposure, with complete recovery within 1-2 h; although usually readily reversible by inhaled beta $_{2}$-agonists, they are actually the most dangerous, as they can be severe and unpredictable, particularly in subjects for whom skin tests with the suspecting agent
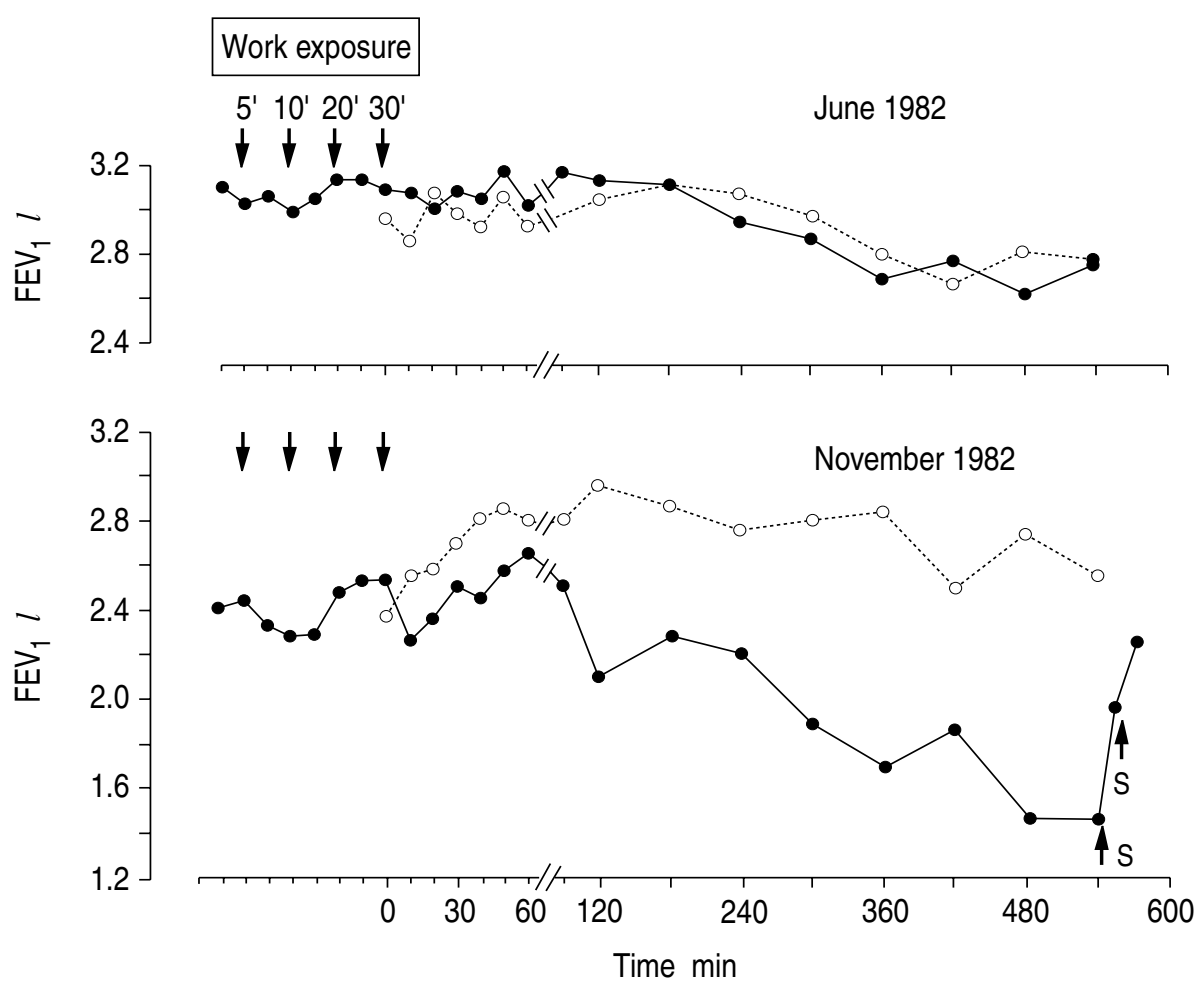

Fig. 3 - Specific inhalation challenges carried out in the same snow-crab processing worker: a) in June 1982, after almost 1 year off work; and b) in November 1982, after reappearance of symptoms on return to work. Whilst the first exposure was not associated with greater changes than on control day, return to work was followed within a few weeks by recurrence of asthma. Repeated specific bronchial challenge in the workplace was then associated with a late asthmatic reaction. Note variation in time axis. $\quad \cdots .-\cdots$. : values obtained on control days; $\longrightarrow$ : values obtained on exposure days. S: salbutamol inhalation. $\mathrm{FEV}_{1}$ : forced expiratory volume in one second. (Reprinted from [18]). 


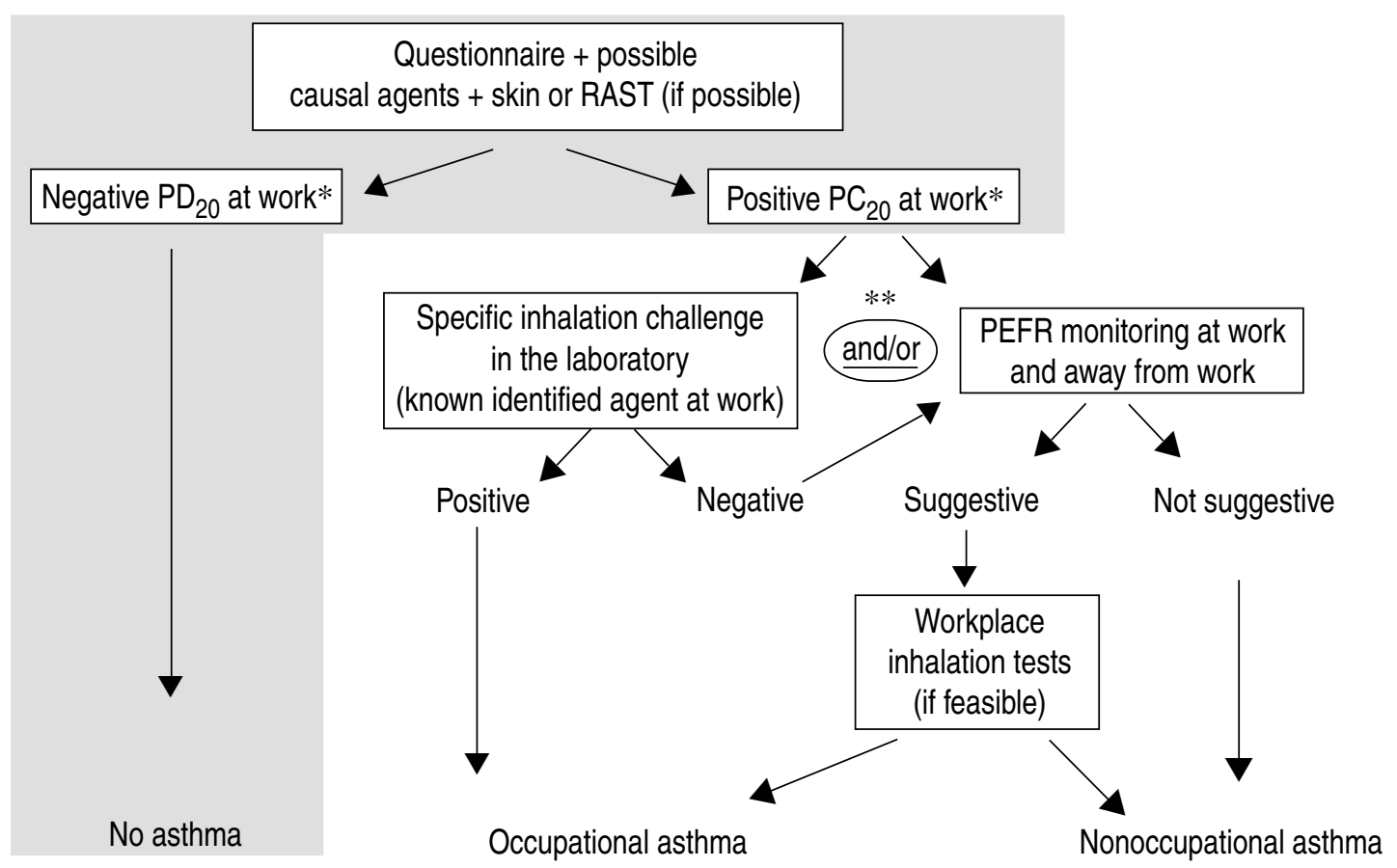

Fig. 4. - Stepwise scheme for the clinical investigation of occupational asthma. The white zone corresponds to the investigation that should be carried out in specialized centres, and the grey zone represents the steps that should be followed by allergologists pneumologists and internists in the initial step of the investigation. RAST: radio-allergosorbent test; PEFR: peak expiratory flow rate. *: assessed at the end of a working day and after a minimal period of 2 weeks at work; **: the choice depends on the facilities of the investigation centre. (Reprinted from [56, 57] by courtesy of Marcel Dekker Inc.

are not possible, stressing the importance of progressive exposure. "Late reactions" develop slowly and progressively, either 1-2 h ("early late") or 4-8 h ("late") after exposure; they may occasionally be accompanied by fever and general malaise but extrinsic alveolitis should then be considered. Contrary to popular belief, they generally respond well to inhaled beta ${ }_{2}$-agonist [53], although the response may be of shorter duration in some subjects. "Dual reactions" are a combination of early and late. A recurrent nocturnal asthma pattern has also been described and is probably related to increase in NABR following exposure [54, 55].

Atypical patterns have also been described with isocyanates and other low or high molecular weight chemicals [52, 54] (fig. 2b): they include the "progressive" type (starting within minutes of end of exposure and progressing over the next 7-8 h); the "square-waved" reaction (with no recovery between the immediate and late components of the reaction); and finally the "prolonged immediate" type with slow recovery. Low molecular weight chemicals are more often associated with atypical patterns than high molecular weight chemicals.

Tests in the workplace are also performed stepwise, as workers may experience a significant fall in FEV Spirometry is followed in the same way throughout the day $[18,45]$.

A negative test in the workplace, or in the laboratory, does not absolutely rule out the diagnosis of occupational asthma in a worker who has not been exposed to work for several months, as he may have become "desensitized" (fig. 3) [18]. The worker should be returned to work with monitoring of PEF and bronchial responsiveness for at least a few weeks before excluding the diagnosis. False negative challenges in the laboratory may also be due to exposure to the wrong agent.

\section{Conclusion}

The diagnosis of occupational asthma should be based on objective means and cannot rely on history alone or even on confirming the presence of asthma and positive skin tests to crab allergens. Figure 4 summarizes the different steps that should be followed to investigate a worker suspected of occupational asthma.

\section{References}

1. Meredith S, Taylor V, McDonald J. - Occupational respiratory disease in the United Kingdom 1989: a report to the British Thoracic Society and the Society of Occupational Medicine by the SWORD project group. Br J Ind Med 1991; 48: 292-298.

2. Malo JL. - Compensation for occupational asthma in Quebec. Chest 1990; 98: 236S-239S.

3. Newman Taylor AJ. - Occupational asthma. Thorax 1980; 35: 241-245.

4. Chan-Yeung M, Malo JL. - Occupational asthma. Chest 1987; 91: 130S-136S.

5. Warren CP, Hargreave FE. - Occupational asthma: definition, diagnosis and management. Can Med Assoc $J$ 1985; 133: 851-4 and 875.

6. Bernstein IL, Chan-Yeung M, Malo JL, Bernstein DI. Definition and classification of asthma. In: Bernstein IL, Chan-Yeung M, Malo JL, Bernstein DI, eds. Asthma in 
the Workplace. New York, Marcel Dekker Inc., 1993; pp. $1-4$.

7. Pauli G, Bessot JC, Dietemann-Molard A. - Occupational asthma: investigation and aetiological factors. Bull Eur Physiopathol Respir 1986; 22: 339-425.

8. Brooks S, Weiss M, Bernstein I. - Reactive airways dysfunction syndrome (RADS); persistent asthma syndrome after high level irritant exposures. Chest 1985; 88: 376384.

9. Brooks SM, Bernstein IL. - Reactive airways dysfunction syndrome or irritant-induced asthma. In: Bernstein IL, Chan-Yeung M, Malo JL, Bernstein DI, eds. Asthma in the Workplace. New York, Marcel Dekker Inc., 1993; pp. 533-549.

10. Merchant JA, Bernstein IL. - Cotton and other textile dusts. In: Bernstein IL, Chan-Yeung M, Malo JL, Bernstein DI, eds. Asthma in the Workplace. New York, Marcel Dekker Inc., 1993; pp. 551-576.

11. Chan-Yeung M, Lam S, Koener S. - Clinical features and natural history of occupational asthma due to western red cedar (Thuja plicata). Am J Med 1982; 72: 411-415.

12. Hudson P, Cartier A, Pineau L, et al. - Follow-up of occupational asthma caused by crab and various agents. J Allergy Clin Immunol 1985; 76: 682-688.

13. Ad hoc Committee on Occupational Asthma of the Standards Committee C. - Occupational asthma: recommendations for diagnosis, management and assessment of impairment. Can Med Assoc J 1989; 140: 1029-1032.

14. Chan-Yeung M, Lam S. - Occupational asthma. Am Rev Respir Dis 1986; 133: 686-703.

15. Chan-Yeung M, Desjardins A. - Bronchial hyperresponsiveness and level of exposure in occupational asthma due to western red cedar (Thuja plicata). Serial observations before and after development of symptoms. Am Rev Respir Dis 1992; 146: 1606-1609.

16. Malo JL, Ghezzo H, D'Aquino C, L'Archevêque J, Cartier A, Chan-Yeung M. - Natural history of occupational asthma: relevance of type of agent and other factors in the rate of development of symptoms in affected subjects. J Allergy Clin Immunol 1992; 90: 937-944.

17. Malo JL, Ghezzo H, L'Archevêque J, Lagier F, Perrin B, Cartier A. - Is the clinical history a satisfactory means of diagnosing occupational asthma? Am Rev Respir Dis 1991; 143: 528-532.

18. Cartier A, Malo JL, Forest F, et al. - Occupational asthma in snow crab-processing workers. J Allergy Clin Immunol 1984; 74: 261-269.

19. Séguin P, Allard A, Cartier A, Malo JL. - Prevalence of occupational asthma in spray painters exposed to several types of isocyanates, including polymethylene polyphenylisocyanate. J Occup Med 1987; 29: 340-344.

20. Malo JL, Cartier A. - Occupational asthma in workers of a pharmaceutical company processing spiramycin. Thorax 1988; 43: 371-377.

21. Bardy JD, Malo JL, Séguin P, et al. - Occupational asthma and IgE sensitization in a pharmaceutical company processing psyllium. Am Rev Respir Dis 1987; 135: 1033-1038.

22. Burge PS. - Single and serial measurements of lung function in the diagnosis of occupational asthma. Eur $J$ Respir Dis 1982; 63(Suppl. 123): 47-59.

23. Cockcroft DW, Mink JT. - Isocyanate-induced asthma in an automobile spray painter. Can Med Assoc J 1979; 121: 602-604.

24. Hargreave FE, Ramsdale EH, Pugsley SO. - Occupational asthma without bronchial hyperresponsiveness. Am Rev Respir Dis 1984; 130: 513-515.
25. Smith A, Brooks S, Blanchard J, Bernstein I, Gallagher J. - Absence of airway hyperreactivity to methacholine in a worker sensitized to toluene diisocyanate. J Oсcup Med 1980; 22: 327-331.

26. Cartier A, Malo JL, Ghezzo H, McCants M, Lehrer SB. - IgE sensitization in snow crab-processing workers. $J$ Allergy Clin Immunol 1986; 78: 344-348.

27. Cartier A, Grammer L, Malo JL, et al. - Specific serum antibodies against isocyanates: association with occupational asthma. J Allergy Clin Immunol 1989; 84: 507-514.

28. Tse KS, Chan H, Chan-Yeung M. - Specific IgE antibodies in workers with occupational asthma due to western red cedar. Clin Allergy 1982; 12: 249-258.

29. Burge PS, O'Brien I, Harries M. - Peak flow rate records in the diagnosis of occupational asthma due to isocyanates. Thorax 1979; 34: 317-323.

30. Burge PS, O'Brien I, Harries M. - Peak flow rate records in the diagnosis of occupational asthma due to colophony. Thorax 1979; 34: 308-316.

31. Cartier A, Pineau L, Malo JL. - Monitoring of maximum expiratory peak flow rates and histamine inhalation tests in the investigation of occupational asthma. Clin Allergy 1984; 14: 193-196.

32. Côté J, Kennedy S, Chan-Yeung M. - Sensitivity and specificity of $\mathrm{PC}_{20}$ and peak expiratory flow rate in cedar asthma. J Allergy Clin Immunol 1990; 85: 592-698.

33. Perrin B, Lagier F, L'Archevêque J, et al. - Occupational asthma: validity of monitoring of peak expiratory flow rates and nonallergic bronchial responsiveness as compared to specific inhalation challenge. Eur Respir J 1992; 5: 40-48.

34. Malo JL, Côté J, Cartier A, Boulet LP, L'Archevêque J, Chan-Yeung M. - How many times per day should peak expiratory flow rate (PEFR) be assessed when investigating occupational asthma (Abstract). Am Rev Respir Dis 1993; 147: A111.

35. Côté J, Kennedy S, Chan-Yeung M. - Quantitative versus qualitative analysis of peak expiratory flow in occupational asthma. Thorax 1993; 48: 48-51.

36. Bérubé D, Cartier A, L'Archevêque J, Ghezzo H, Malo JL. - Comparison of peak expiratory flow rate and $\mathrm{FEV}_{1}$ in assessing bronchomotor tone after challenges with occupational sensitizers. Chest 1991; 99: 831-836.

37. Gautrin D, Cartier A, D'Aquino LC, Gagnon G, Malo JL. - Reliability of peak expiratory flow rates (PEFR) compared to $\mathrm{FEV}_{1}$ in the assessment of out-patient asthmatics (Abstract). Am Rev Respir Dis 1993; 147: A995.

38. Chan-Yeung M. - Nonspecific bronchial hyperresponsiveness. In: Bernstein IL, Chan-Yeung $\mathrm{M}$, Malo JL, Bernstein DI, eds. Asthma in the Workplace. New York, Marcel Dekker Inc., 1993; pp. 189-214.

39. Cartier A, Malo JL. - Occupational challenge tests. In: Bernstein IL, Chan-Yeung M, Malo JL, Bernstein DI, eds. Asthma in the Workplace. New York, Marcel Dekker Inc., 1993; pp. 215-248.

40. EAACI. - Guidelines for the diagnosis of occupational asthma. Subcommittee on "Occupational Allergy" of the European Academy of Allergology and Clinical Immunology. Clin Exp Allergy 1992; 22: 103-108.

41. Cartier A, Bernstein IL, Burge PS, et al. - Guidelines for bronchoprovocation on the investigation of occupational asthma. Report of the Subcommittee on Bronchoprovocation for Occupational Asthma. J Allergy Clin Immunol 1989; 84: 823-829.

42. Kopferschmitt-Kubler MC, Pauli G. - Les tests de provocation spécifique. Rev Pneumol Clin 1991; 47: 171-176. 
43. Lam S, Chan-Yeung M. - Occupational asthma: natural history, evaluation and management. Occup Med 1987; 2: 373-381.

44. Pepys J, Hutchcroft BJ. - Bronchial provocation tests in etiologic diagnosis and analysis of asthma. Am Rev Respir Dis 1975; 112: 829-859.

45. Chan-Yeung M, McMurren T, Catonio-Begley F, Lam S. - Occupational asthma in a technologist exposed to glutaraldehyde. J Allergy Clin Immunol 1993; 91: 974-978.

46. Cockcroft DW, Murdock KY, Kirby J, Hargreave FE. Prediction of airway responsiveness to allergen from skin sensitivity to allergen and airway responsiveness to histamine. Am Rev Respir Dis 1987; 135: 264-267.

47. de Luca S, Caire N, Cloutier Y, Cartier A, Ghezzo H, Malo JL. - Acute exposure to sawdust does not alter airway calibre and responsiveness to histamine in asthmatic subjects. Eur Respir J 1988; 1: 540-546.

48. Cloutier Y, Malo JL. - Update on an exposure system for particles in the diagnosis of occupational asthma. Eur Respir J 1992; 5: 887-890.

49. Chan-Yeung M, Barton GM, McLean L, Grzybowski S. - Bronchial reactions to western red cedar (Thuja plicata). Can Med Assoc J 1971; 105: 56-58 and 61.

50. Malo JL, Cartier A, Doepner M, Nieboer E, Evans S, Dolovich J. - Occupational asthma caused by nickel sulfate. J Allergy Clin Immunol 1982; 69: 55-59.

51. Vandenplas O, Malo JL, Cartier A, Perreault G, Cloutier Y. - Closed-circuit methodology for inhalation challenge tests with isocyanates. Am Rev Respir Dis 1992; 145: 582-587.

52. Perrin B, Cartier A, Ghezzo H, et al. - Reassessment of the temporal patterns of bronchial obstruction after exposure to occupational sensitizing agents. J Allergy Clin Immunol 1991; 87: 630-639.

53. Malo JL, Ghezzo H, L'Archevêque J, Cartier A. - Late asthmatic reactions to occupational sensitizing agents: frequency of changes in nonspecific bronchial responsiveness and of response to inhaled beta ${ }_{2}$-adrenergic agent. $J$ Allergy Clin Immunol 1990; 85: 834-842.

54. Zammit-Tabona M, Sherkin M, Kijek K, Chan H, ChanYeung M. - Asthma caused by diphenylmethane diisocyanate in foundry workers. Clinical, bronchial provocation, and immunologic studies. Am Rev Respir Dis 1983; 128: 226-230.

55. Cockcroft DW, Hoeppner VH, Werner GD. - Recurrent nocturnal asthma after bronchoprovocation with Western Red Cedar sawdust: association with acute increase in nonallergic bronchial responsiveness. Clin Allergy 1984; 14: 61-68.

56. Bernstein DI. - Clinical assessment and management of occupational asthma. In: Bernstein IL, Chan-Yeung M, Malo JL, Bernstein DI, eds. Asthma in the Workplace. New York, Marcel Dekker Inc., 1993; pp. 103-123.

57. Malo JL. - The case for confirming occupational asthma: why, how much, how far? J Allergy Clin Immunol 1993; 91: 967-970. 